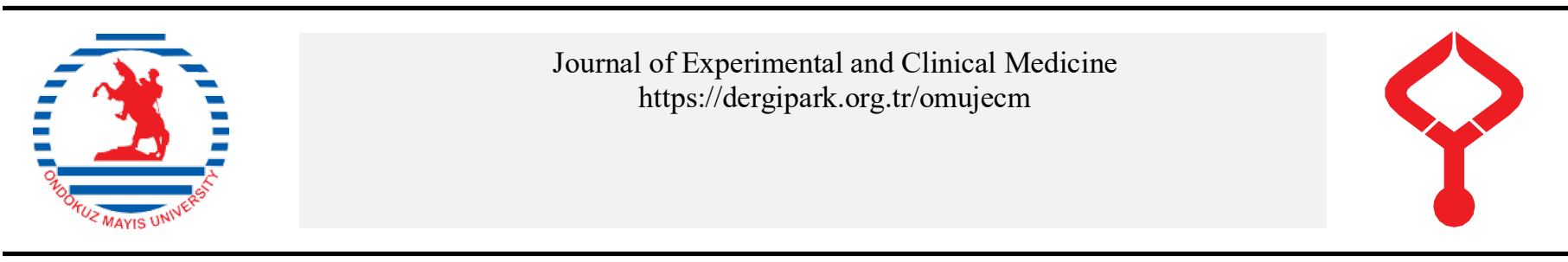

Research Article

$\mathrm{J}$ Exp Clin Med

2021; 38(4): 457-460

doi: 10.52142 /omujecm.38.4.10

\title{
Relationship of inhaled ipratropium and inhaled salbutamol with pupil dilation: A prospective observational study
}

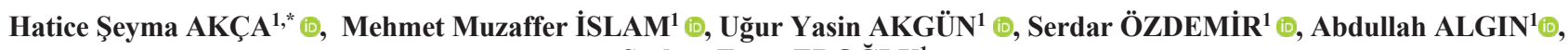 \\ Serkan Emre EROĞLU ${ }^{1}$ (i)
}

${ }^{1}$ Department of Emergency Medicine, Ümraniye Education and Research Hospital, University of Health Sciences, Istanbul, Turkey

\begin{abstract}
\begin{tabular}{lllll}
\hline Received: 01.03 .2021 & $\bullet$ & Accepted/Published Online: 03.03.2021 & Final Version: 30.08 .2021 \\
\hline
\end{tabular}
\section{Abstract}

This prospective randomized study aimed to compare the effects of nebulizer drugs on unilateral or bilateral dilation of the pupil that may develop due to mask incompatibility or patient incompatibility in patients receiving inhaled therapy. Following the approval of the local ethics committee, this study was carried out prospectively and observationally in the period from October 1, 2018 to April 1, 2019 in an emergency clinic with an annual capacity of 600,000 patients in a tertiary education and research hospital. The patients were divided into three groups: those given salbutamol alone $(200 \mathrm{mcg})$, those given ipratropium alone $(250 \mathrm{mcg} / 2 \mathrm{ml})$, and those receiving both salbutamol and ipratropium. The pupil diameters of the patients included in the study were measured twice using a pupilometer device at hours 0 and 2 of treatment. Ninetyone patients that received inhaler treatment in the emergency department were included in the study. The process of treatments given to patients with indications was not interrupted. Ipratropium and salbutamol (49.5\%) were used together in 45 patients, ipratropium alone in 38 (41.7\%), and salbutamol alone in eight $(8.8 \%)$. When the absolute delta ratios were compared, a statistically significant difference was observed between the patients given salbutamol and those given ipratropium, and between the patients that received salbutamol and those given salbutamol and ipratropium ( $\mathrm{p}=0.001,95 \%$ CI: $1.36-6.11$ and $\mathrm{p}<0.001,95 \%$ CI: $1.51-6.19$, respectively). Salbutamol caused statistically significantly greater pupil diameter changes than the other drugs. Although neurological diagnoses are considered in patients with anisocoria, it should be kept in mind that anisocoria may also be due to the current or the treatment being given.
\end{abstract}

Keywords: anisocoria, ipratropium, nebulizer treatment, pupil dilatation, salbutamol

\section{Introduction}

Ipratropium and salbutamol are two agents recommended by the current Global Strategy for the Diagnosis, Management, and Prevention of Chronic Obstructive Lung Disease (GOLD) guidelines for the treatment of chronic obstructive pulmonary disease (COPD) (1). These active substances are usually given to the patient by inhalation (2). For this treatment to be effective, the mask through which the inhaler is applied must fit the face snugly. As a result of an ill-fitting mask, anisocoria cases have been reported in them literature $(3,4$, 5). This situation forces clinicians to make a differential diagnosis on a newly developing neurological pathology and may lead to unnecessary use of resources, as well as unnecessary radiation exposure and/or invasive procedures.

Anisocoria is typically defined as a difference of more than $1 \mathrm{~mm}$ between the diameters of the two pupils, characterized by an abnormally small unilateral pupil in the dark indicating sympathetic damage and an abnormally large unilateral pupil in light suggesting parasympathetic damage $(6,7)$.

Although the development of anisocoria because of the application of inhaler beta agonist or anticholinergic treatment given with an ill-fitting mask is a well-defined clinical entity in case reports, to the best of our knowledge, no related research paper has been published in the literature to date. This prospective randomized study aimed to compare the effects of nebulizer drugs on unilateral or bilateral dilation of the pupil that may develop due to mask incompatibility or patient incompatibility in patients receiving inhaled therapy.

\section{Materials and methods}

Following the approval of the local ethics committee, this study was carried out prospectively and observationally in the period from October 1, 2018, to April 1, 2019 in an emergency clinic with an annual capacity of 600,000 patients in a tertiary education and research hospital. Consent was obtained from the patients included in the study and attention was paid to patient privacy.

Patients who presented to the clinic and were recommended inhaled treatment by clinicians to be administered by nurses were asked to participate in the study. Patients with cataracts, any pupil pathology, sympathomimetic drug use, and a history of acute or previous central nervous system pathology were excluded. The 
researchers did not interfere with the practice of nurses and clinicians performing the treatment. The demographic data (age, gender), comorbidities (hypertension, diabetes mellitus, coronary artery disease, congestive heart failure, chronic kidney disease, active malignancy) and drug groups were recorded. The patients were divided into three groups: those given salbutamol alone $(200 \mathrm{mcg})$, those given ipratropium alone $(250 \mathrm{mcg})$, and those receiving both salbutamol and ipratropium. Since salbutamol reaches a peak level in 15-30 minutes and continues its effect until 4-6 hours and ipratropium reaches a peak level for 1-2 hours and continues its effect for 6-8 hours, the reference time interval is taken as the $2^{\text {nd }}$ hour. The pupil diameters of the patients included in the study were measured twice using a pupilometer device at hours $0^{\text {th }}$ and $2^{\text {nd }}$ of treatment. The right and left pupil diameter measurements of the patient groups were undertaken separately. The location of the patients and the amount of light in the room were not changed during the treatment. The examinations, follow-up and treatments of the patients were performed in an environment at $22 \pm 3{ }^{\circ} \mathrm{C}$ exposed to the same light dose without any change in the location. This partly allowed to obtain pupil diameter changes dependent on the drug. The difference between the diameters of the right and left pupils before and two hours after treatment was recorded as absolute delta. The relationship between the absolute delta values of the groups was statistically evaluated.

Statistical analysis was performed using SPSS version 26. The suitability of variables to normal distribution was examined by visual (histogram and probability graphs) and analytical methods (Kolmogorov-Smirnov/Shapiro-Wilk tests). Normally distributed continuous data were expressed using mean and standard deviation values, while the data without normal distribution were obtained as median and interquartile ranges. Categorical data were indicated by frequency and percentages. The comparison between the groups was undertaken using Student's t-test for the independent continuous data with normal distribution, paired t-test for dependent continuous data, the Mann-Whitney $U$ test for the independent continuous data without normal distribution, and the Wilcoxon test for the dependent continuous data without normal distribution. One-way analysis of variance (ANOVA) was conducted to compare multiple continuous data. The statistical significance level was accepted as $\mathrm{p}<0.05$.

\section{Results}

A total of 99 patients received inhaler treatment in our emergency department from October 1, 2018 and April 1, 2019. Two of these patients were excluded because they had anisocoria before treatment, and six were excluded due to cataracts. Thus, 91 patients were evaluated in the study. Fiftyone $(56 \%)$ patients were male and $40(44 \%)$ were female. The process of treatments given to patients with indications was not interrupted. Ipratropium and salbutamol were used in 45 (49.5\%) patients, ipratropium alone in 38 (41.7\%), and salbutamol alone in eight $(8.8 \%)$ (Table 1).

The right and left pupil diameters of the patients were compared before and two hours after treatment, and the data were analyzed with the Wilcoxon test. Accordingly, no statistically significant difference was found in the group that was given salbutamol alone $(\mathrm{p}=0.499$ and $\mathrm{p}=0.528$, respectively) and in the group given ipratropium alone $(\mathrm{p}=0.482$ and $\mathrm{p}=0.383$, respectively). In the group receiving both salbutamol and ipratropium, there was no statistically significant difference for the right pupils $(\mathrm{p}=0.464)$ while a statistically significant difference was observed for the left pupils ( $\mathrm{p}=0.011)$ (Table 2).

Table 1. Descriptive characteristics of the patients $(n=91)$

\begin{tabular}{|l|c|c|}
\hline Age (median) & 67 & (IQR 55-80) \\
\hline Gender(total) & 91 & $(100 \%)$ \\
\hline Male & 51 & $(56 \%)$ \\
\hline Female & 40 & $(44 \%)$ \\
\hline Patients (total) & 91 & $(100 \%)$ \\
\hline Patients given salbutamol alone & 8 & $(8.8 \%)$ \\
\hline Patients given ipratropium alone & 38 & $(41.7 \%)$ \\
\hline Patients given salbutamol + & 45 & $(49.5 \%)$ \\
ipratropium & & $\mathrm{n}(\%)$ \\
\hline Comorbidities & 39 & $(42.85 \%)$ \\
\hline Hypertension & 23 & $(25.2 \%)$ \\
\hline Diabetes mellitus & 23 & $(25.2 \%)$ \\
\hline Coronary artery disease & 19 & $(20.8 \%)$ \\
Congestive heart failure & 3 & $(3.3 \%)$ \\
Chronic kidney disease & 5 & $(5.5 \%)$ \\
\hline Active malignancy & &
\end{tabular}

$\mathrm{IQR}$, interquartile range

Table 2. Analysis of the right and left pupil diameter changes in patients receiving salbutamol alone, ipratropium alone, and combined therapy

\begin{tabular}{|l|c|c|}
\hline Therapy & $\begin{array}{c}\text { Right pupil diameter } \\
\text { Change }\end{array}$ & $\begin{array}{c}\text { Left pupil diameter } \\
\text { Change }\end{array}$ \\
\hline Salbutamol alone & $0.093 \mathrm{~mm}( \pm 0.125)$ & $-0.128 \mathrm{~mm}( \pm 0.128)$ \\
\hline $\mathrm{p}$ value & $\mathrm{P}=0.499$ & $\mathrm{p}=0.528$ \\
Ipratropium alone & $0.005 \mathrm{~mm}$ & $-0.01 \mathrm{~mm}$ \\
$(-0.03)-(0.06)$ & $(-0.032)-(0.052)$ \\
\hline $\mathrm{p}$ value & $\mathrm{p}=0.482$ & $\mathrm{P}=0.383$ \\
\hline $\begin{array}{c}\text { Salbutamol }+ \\
\text { ipratropium }\end{array}$ & $0.01 \mathrm{~mm}$ & $-0.02 \mathrm{~mm}$ \\
\hline $\begin{array}{c}\mathrm{p} \text { value } \\
\text { IQR, interquartile range }\end{array}$ & $\mathrm{P}=0.464$ & $(-0.01)-(0.075)$ \\
\hline
\end{tabular}

According to the Mann-Whitney $U$ test, there was no statistically significant difference in the changes in the right and left pupil diameters between the salbutamol alone and ipratropium alone groups $(\mathrm{p}=0.212$ and $\mathrm{p}=0.582$, respectively), between the salbutamol alone and salbutamol + ipratropium groups $(\mathrm{p}=0.209, \mathrm{p}=0.921$, respectively), and between the ipratropium alone and salbutamol + ipratropium groups ( $\mathrm{p}=0.898$ and $\mathrm{p}=0.318$, respectively). The mean pupil diameter was comparatively evaluated before and two hours after treatment using the paired t-test. According to the results, the differences in the mean pupil diameter between 
the two measurement times were not statistically significant in any of the three groups $(\mathrm{p}=0.683,95 \%$ confidence interval (CI): $(-0.779)-(1.147)$ for salbutamol alone; $\mathrm{p}=0.528,95 \%$ CI: (-0.259) -(0.153) for ipratropium alone; and $\mathrm{p}=0.159$, 95\% CI: (-0.046) -(0.272) for salbutamol + ipratropium) (Table 3).The mean absolute delta values were $0.550 \mathrm{~mm}$ $( \pm 0.146)$ for the patients given salbutamol alone, $0.175 \mathrm{~mm}$ $( \pm 0.039)$ for those receiving ipratropium alone, and $0.164 \mathrm{~mm}$ $( \pm 0.032)$ for those in the salbutamol + ipratropium group. The relationship between these variables was compared using one-way ANOVA, and no statistically significant difference was found in the post-hoc analysis between the patients those given ipratropium alone and those given salbutamol + ipratropium ( $p>0.001)$. A statistically significant difference was found in the post-hoc analysis between the patients given salbutamol alone and those given ipratropium alone (Table 4), as well as between those given salbutamol alone and those given salbutamol + ipratropium (Table 5) $(\mathrm{p}=0.001,95 \% \mathrm{CI}$ : 1.36- 6.11 and $\mathrm{p}<0.001$, 95\% CI: $1.51-6.19$, respectively). Thus, no drug produced a statistically significant difference between the mean pupil diameters measured before and after treatment, but when the total pupil diameter change caused by the drugs was compared numerically, the pupil diameter of the group receiving salbutamol alone was significantly higher than the other drug groups; thus, salbutamol led to statistically significant changes in the pupil diameter.

Table 3. Analysis of the mean pupil diameter changes in patients receiving salbutamol alone, ipratropium alone, and combined therapy

\begin{tabular}{|l|c|c|c|}
\hline Therapy & $\begin{array}{c}\text { Mean pupil } \\
\text { diameter } \\
\text { at hour } 0\end{array}$ & $\begin{array}{c}\text { Mean pupil } \\
\text { diameter } \\
\text { at hour } 2\end{array}$ & p value \\
\hline Salbutamol & $\begin{array}{c}3.182 \mathrm{~mm} \\
( \pm 0.058 \mathrm{~mm})\end{array}$ & $\begin{array}{c}3.165 \mathrm{~mm} \\
( \pm 0.086 \mathrm{~mm})\end{array}$ & $\begin{array}{c}95 \% \mathrm{CI} \text { : } \\
(-0.797)-(1.147)\end{array}$ \\
\hline Ipratropium & $\begin{array}{c}3.259 \mathrm{~mm} \\
( \pm 0.034 \mathrm{~mm})\end{array}$ & $\begin{array}{c}3.265 \mathrm{~mm} \\
( \pm 0.035 \mathrm{~mm})\end{array}$ & $\begin{array}{c}95 \% \mathrm{CI} \\
(-0.259)-(0.135)\end{array}$ \\
\hline $\begin{array}{l}\text { Salbutamol }+ \\
\text { Ipratropium }\end{array}$ & $\begin{array}{c}3.232 \mathrm{~mm} \\
( \pm 0.030 \mathrm{~mm})\end{array}$ & $\begin{array}{c}3.221 \mathrm{~mm} \\
( \pm 0.030 \mathrm{~mm})\end{array}$ & $\begin{array}{c}95 \% \mathrm{CI}: \\
(-0.046)-(0.272)\end{array}$ \\
\hline
\end{tabular}

Table 4. Comparison of the pupil diameter absolute delta values of patients receiving salbutamol alone and ipratropium alone

\begin{tabular}{|l|c|c|}
\hline Drug & Absolute delta value & $\mathrm{p}$ value \\
\hline Salbutamol & $0.550 \mathrm{~mm}( \pm 0.146)$ & $\mathrm{p}=0.001$ \\
\hline Ipratropium & $0.175 \mathrm{~mm}( \pm 0.039)$ & $95 \% \mathrm{CI}: 1.36-6.11$ \\
\hline
\end{tabular}

CI, confidence interval

Table 5. Comparison of the pupil diameter absolute delta values of patients receiving salbutamol alone and salbutamol + ipratropium

\begin{tabular}{|l|c|c|}
\hline \multicolumn{1}{|c|}{ Drug } & Absolute delta value & p value \\
\hline Salbutamol & $0.550 \mathrm{~mm}( \pm 0.146)$ & $\begin{array}{c}\mathrm{p}<0.001 \\
95 \% \quad \text { CI: }\end{array}$ \\
\hline $\begin{array}{l}\text { Salbutamol }+ \\
\text { ipratropium }\end{array}$ & $0.164 \mathrm{~mm}( \pm 0.032)$ & $1.51-6.19$ \\
\hline
\end{tabular}

CI, confidence interval

\section{Discussion}

In this study, while no drug treatment produced a statistically significant difference in terms of the mean pupil diameter before and after treatment, salbutamol alone was found to lead to statistically significantly greater change in the total pupil diameter (delta) compared to the other drug groups. The fact that salbutamol caused more pupil dilation than ipratropium and combined treatment was important in terms of revealing that salbutamol may also be related to anisocoria cases that are often associated with ipratropium. In this study, we aimed to compare the effects of nebulizer drugs on unilateral or bilateral pupil dilatation due to mask incompatibility or patient incompatibility in patients receiving inhaled therapy. There are few studies related to drugs that cause anisocoria associated with pathologies other than central nervous system pathology, and there are many case reports. Apraclonidine may rarely cause anisocoria by acting on alpha receptors (8). Cocaine can cause anisocoria by inhibiting noradrenaline re-uptake and affecting only the sympathetic nervous system (9). Kuhn et al. detected dilatation in the right pupil diameter 30 minutes after the application of $2 \%$ concentration of isoflurane they used during induction in a girl they operated due to hiatal hernia (10). Similarly, in a case report reported by Akhlaghi, unilateral anisocoria occurring 30 minutes after the use of pofol, an anesthesia induction agent was reported in a patient undergoing surgery for an open extremity fracture (11).

To date, many case reports of unilateral mydriasis due to nebulized ipratropium have been reported (12-14). In a previous study, unilateral mydriasis developed in one patient who received salbutamol + ipratropium due to mask leakage after thoracic operation, and it was stated that in addition to unilateral pupil dilatations due to ipratropium, mydriasis could develop because of salbutamol (15). In another study, unilateral mydriasis was reported in a seven-month-old infant receiving combined therapy (16). In our study, it was found that inhaler agents cause mydriasis, and no statistically significant relationship was found in the analysis of the effect of single and combined forms on mean pupil diameter change.

A female patient receiving salbutamol and ipratropium was reported to develop acute glaucoma lasting four days in both eyes (17). Similar acute glaucoma cases related to combined therapy have been described $(18,19)$. In a previous study, intraocular pressures measured at the second hour of salbutamol, ipratropium, and combined nebulizer therapy were compared, and in patients with narrow angle glaucoma, intraocular pressure was found to be statistically significantly increased after combined therapy (20). Similarly, in our study, when compared in terms of the effect of salbutamol, ipratropium, and their combined forms on total pupil diameter, it was found that the salbutamol group caused statistically significantly more changes in pupil diameter compared to other drug groups. In a study conducted in rats, it 
was observed that inhaled ipratropium did not cause a statistically significant change in pupil dilatation (21). Our study is the first to show that salbutamol may also cause pupil dilation in inhaled therapy, like ipratropium. In this study, a limited number of cases were investigated due to several factors, such as patient non-compliance, the inability to use nebulizers at the appropriate time due to the patients' need for continuous positive airway pressure and follow-up being undertaken without changing the patient location in the emergency department. Although neurological diagnoses are considered in patients with anisocoria, it should be kept in mind that anisocoria may also be due to the current or the treatment being given. We think that our study may be a guide for clinicians in terms of delaying immediate application to examinations aimed at excluding central events unrelated to the examination, especially in patients receiving inhaler therapy, in the case of anisocoria that is not detected at the first examination, may be due to a mask that is not fully fitted to the face.

\section{Conflict of interest}

No conflict of interest between authors.

\section{Funding}

No funding.

\section{References}

1. Vogelmeier CF, Criner GJ, Martinez FJ, Anzueto A, Barnes PJ, Bourbeau J, et al. Global Strategy for the Diagnosis, Management, and Prevention of Chronic Obstructive Lung Disease 2017 Report. GOLD Executive Summary. Am J Respir Crit Care Med. 2017; 195(5):557-582. doi: 10.1164/rccm.201701-0218PP.

2. Zhang R, Hu J, Deng L, Li S, Chen X, Liu F, et al. Aerosol Characteristics and Physico-Chemical Compatibility of Combivent ${ }^{\circledR}$ (Containing Salbutamol and Ipratropium Bromide) Mixed with Three Other Inhalants: Budesonide, Beclomethasone or N-Acetylcysteine. Pharmaceutics. 2020; 12(1):78. doi: 10.3390/pharmaceutics 12010078 .

3. Iosson N. Images in clinical medicine. Nebulizer-associated anisocoria. $\mathrm{N}$ Engl J Med. 2006; 354(9): e8. doi: 10.1056/NEJMicm050851.

4. Wehbe E, Antoun SA, Moussa J, Nassif I. Transient anisocoria caused by aerosolized ipratropium bromide exposure from an illfitting face mask. J Neuroophthalmol. 2008;28(3):236-7. doi: 10.1097/WNO.0b013e318175cb94.

5. Kokulu K, Öner H, Özen C, Eroğlu SE, Altunok İ, Akça HŞ. Pharmacologic anisocoria due to nebulized ipratropium bromide: A diagnostic challenge. Am J Emerg Med. 2019; 37(6): 1217.e31217.e4. doi: 10.1016/j.ajem.2019.03.047.

6. Falardeau J. Anisocoria. Int Ophthalmol Clin. 2019; 59(3):12539. doi: 10.1097/IIO.0000000000000276.
7. Gross JR, McClelland CM, Lee MS. An approach to anisocoria. Curr Opin Ophthalmol. 2016; 27(6):486-92. doi: 10.1097/ICU.0000000000000316.

8. Robin AL. Short-term effects of unilateral $1 \%$ apraclonidine therapy. Arch Ophthalmol. 1988; 106(7): 912-5. doi: 10.1001/archopht.1988.01060140058024.

9. Bralliar BB, Skarf B, Owens JB. Ophthalmic use of cocaine and the urine test for benzoylecgonine. N Engl J Med. 1989; 320(26):1757-8. doi: 10.1056/nejm198906293202619.

10. Kuhn I, Wissing H. Anisocoria during isoflurane anaesthesia in a six-year-old girl. Paediatr Anaesth. 1996;6(5):411-3. doi: 10.1046/j.1460-9592. 1996.d01-4.x.

11. Akhlaghi M., 2016. Anisocoria under general anesthesia with Propofol. J Bas Res Med Sci 2016; 3(4):1-3. doi.org/10.18869/acadpub.jbrms.3.4.1

12. Pennington KM, St Louis EK. "Don't Believe Your Eyes" Ipratropium Induced Mydriasis: A Case Report and Review of the Literature. Gen Med (Los Angel). 2016; 4(3):255. doi: 10.4172/2327-5146.1000255.

13. Vatansever Ş, Kutluyurdu B, Sarı ME, Özyuvacı E. Ipratropiium Bromide Induced Acute Anisocoria. İstanbul Med J. 2009; 1, 534.

14. Jannun DR, Mickel SF. Anisocoria and aerosolized anticholinergics. Chest. 1986; 90(1):148-9. doi: 10.1378/chest.90.1.148.

15. Raut MS, Maheshwari A, Shivnani G, Kumar A. Unilateral Dilated Fixed Pupil after Thoracic Surgery: Need for Concern? J Cardiothorac Vasc Anesth. 2017; 31(4): e60-e61. doi: 10.1053/j.jvca.2017.02.033.

16. Kara N, Çelik S, Gürpınar G, Dalgıç N, Kafadar İ. Anisocoria in a Patient with Acute Bronchiolitis. J Pediatr Inf. 2018; 12, 32-4.

17. Kola M, Hacığlu D, Erdöl H, Türk A. Bilateral acute angle closure developing due to use of ipratropium bromide and salbutamol. Int Ophthalmol. 2018; 38(1): 385-8. doi: 10.1007/s10792-017-0458-x.

18. Shah P, Dhurjon L, Metcalfe T, Gibson JM. Acute angle closure glaucoma associated with nebulised ipratropium bromide and salbutamol. BMJ. 1992; 304(6818):40-1. doi: 10.1136/bmj.304.6818.40.

19. De Saint Jean M, Bourcier T, Borderie V, Moldovan M, Touzeau $\mathrm{O}$, Laroche L. Glaucome aigu par fermeture de l'angle après un traitement par aérosols de bromure d'ipratropium et de salbutamol [Acute closure-angle glaucoma after treatment with ipratropium bromide and salbutamol aerosols]. J Fr Ophtalmol. 2000; 23(6):603-5. French. PMID: 10880928.

20. Kalra L, Bone MF. The effect of nebulized bronchodilator therapy on intraocular pressures in patients with glaucoma. Chest. 1988; 93(4):739-41. doi: 10.1378/chest.93.4.739.

21. Akça HŞ, İhtiyar B, Kokulu K, Algın A, Özdemir S, Eroğlu SE, et al. Effect of Ipratropium Inhalation on Pupil Dilatation in Rats. Eurasian J Emerg Med. 2021; 20:39-42. doi: 10.4274/eajem.galenos.2020.29494 